\title{
Supplementary figures for: One size fits all? - Calibrating an ocean biogeochemistry model for different circulations
}

Iris Kriest ${ }^{1}$, Paul Kähler ${ }^{1}$, Wolfgang Koeve ${ }^{1}$, Karin Kvale ${ }^{1}$, Volkmar Sauerland ${ }^{1,2}$, and Andreas Oschlies ${ }^{1}$ ${ }^{1}$ GEOMAR Helmholtz-Zentrum für Ozeanforschung Kiel, Düsternbrooker Weg 20, D-24105 Kiel, Germany

${ }^{2}$ Department of Mathematics, Kiel University, Christian-Albrechts-Platz 4, D-24118 Kiel, Germany

Correspondence: Iris Kriest (ikriest@geomar.de) 
$25 \mathrm{~m}, \sigma_{\tau}$
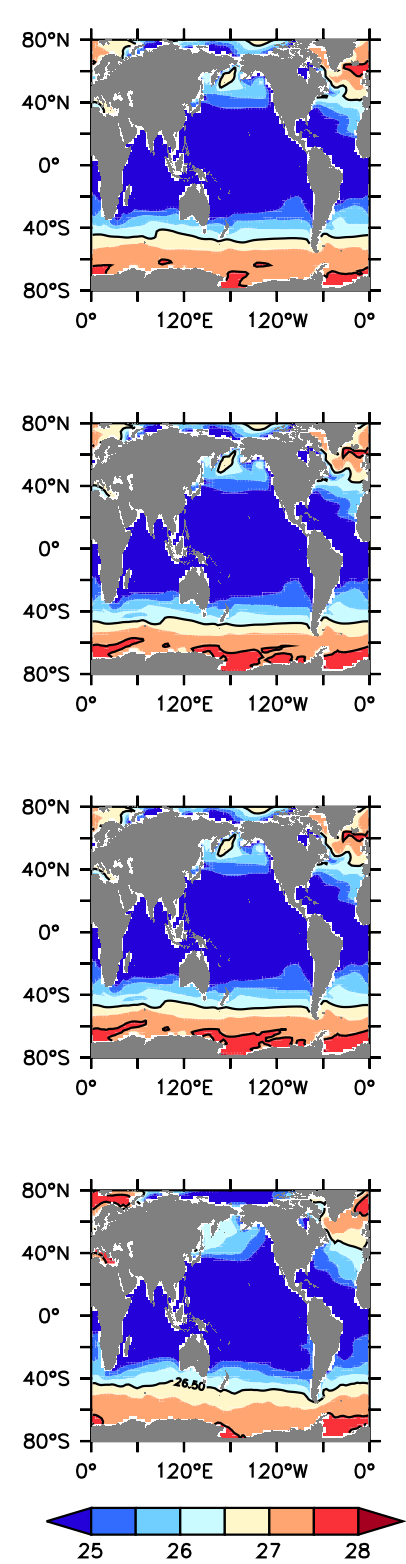

Atlantic, $23 W$

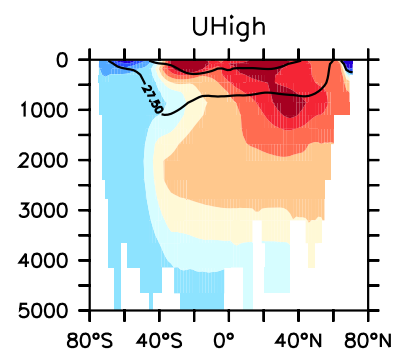

U20

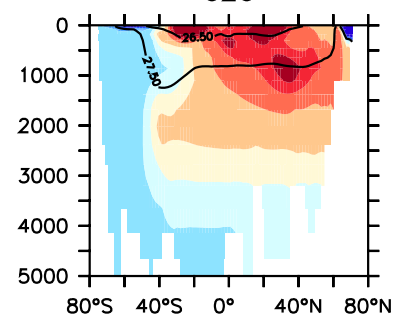

U17.5
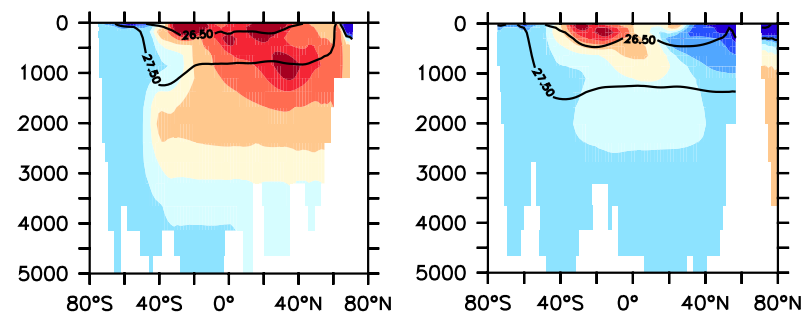

Observations (on UVic grid)

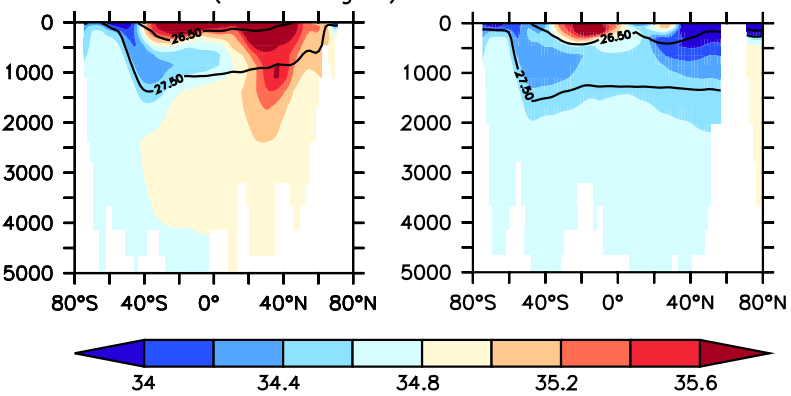

Figure S1. Density at $25 \mathrm{~m}$ (left panels), and salinity along sections at $23^{\circ} \mathrm{W}$ and $140^{\circ} \mathrm{W}$ (middle and right panels), of circulations (top to bottom) UHigh, U20 and U17.5 circulation. The lower panel shows observations mapped onto UVic geometry. Density has been derived from annual mean potential temperature and salinity. Contour lines in left panels highlight isopycnal of $\sigma_{\theta}=26.5$ and $\sigma_{\theta}=27.5$. 


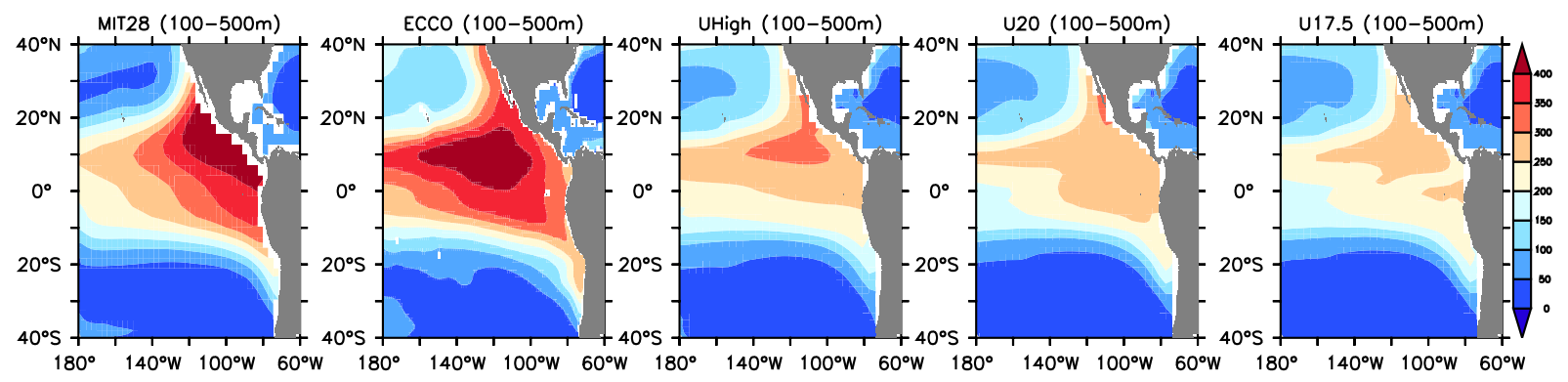

Figure S2. Ideal age averaged over 150 to $500 \mathrm{~m}$ in the eastern tropical and subtropical Pacific of (left to right) MIT28, ECCO, UHigh, U20 and U17.5. Units are in years. 
Atlantic

\section{MIT28*}
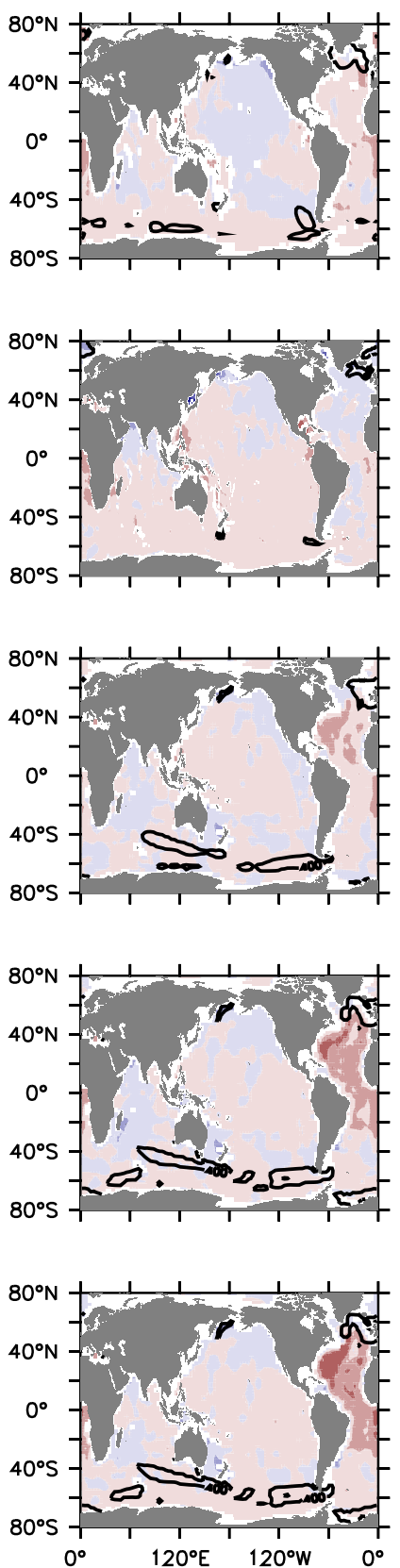

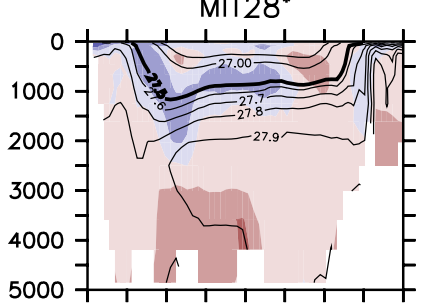

ECCO*

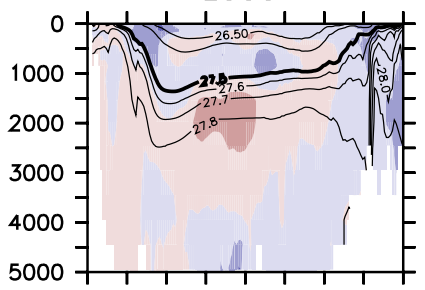

UHigh*

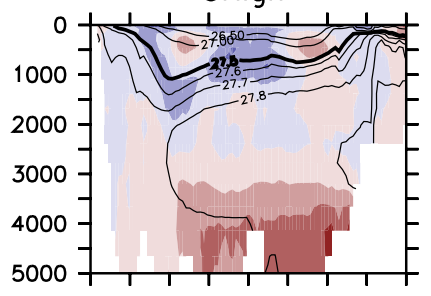

U20*

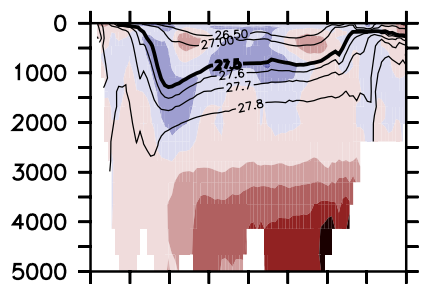

U17.5*

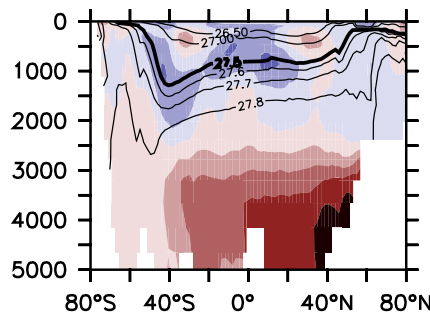

Pacific
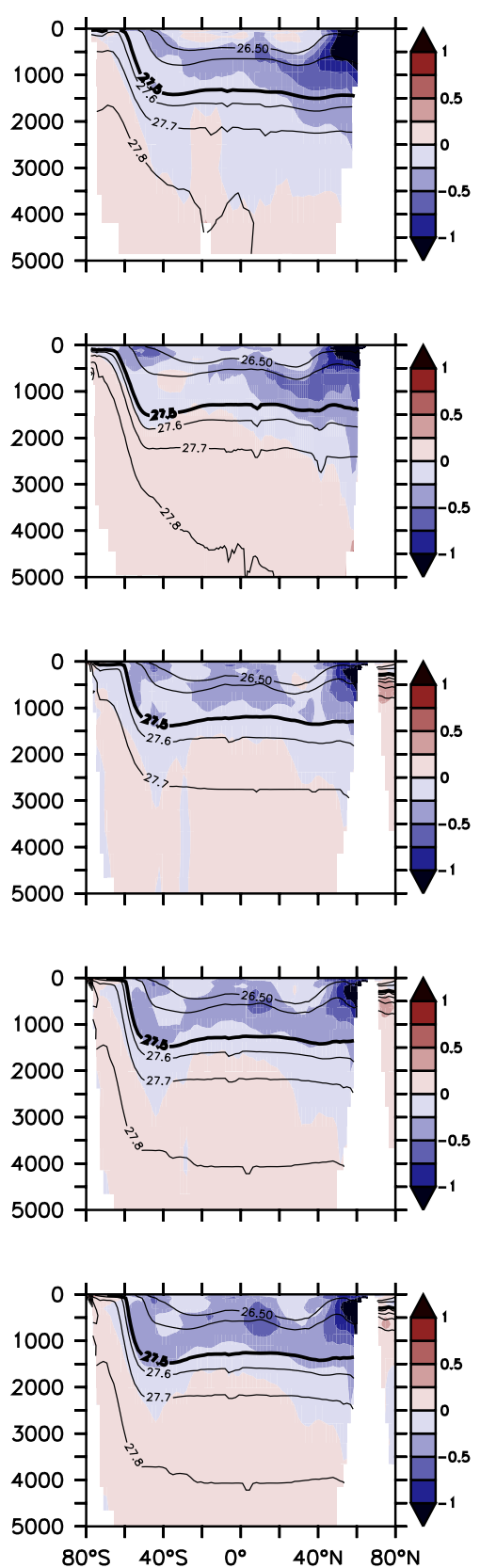

Figure S3. Deviation between simulated and observed phosphate of optimised models. Left panels: deviation of nitrate averaged over 1500$5000 \mathrm{~m}$. Middle panels: deviation between zonal mean nitrate in the Atlantic. Right panels: deviation between zonal mean nitrate in the Pacific. Lines in the left panels indicate regions where maximum mixed-layer depth (calculated as in Fig. 2) is equal or larger than 400 m. Lines in the middle and right panels indicate potential density, averaged zonally. Units are in $\mathrm{mmol} \mathrm{m}^{-3}$. 

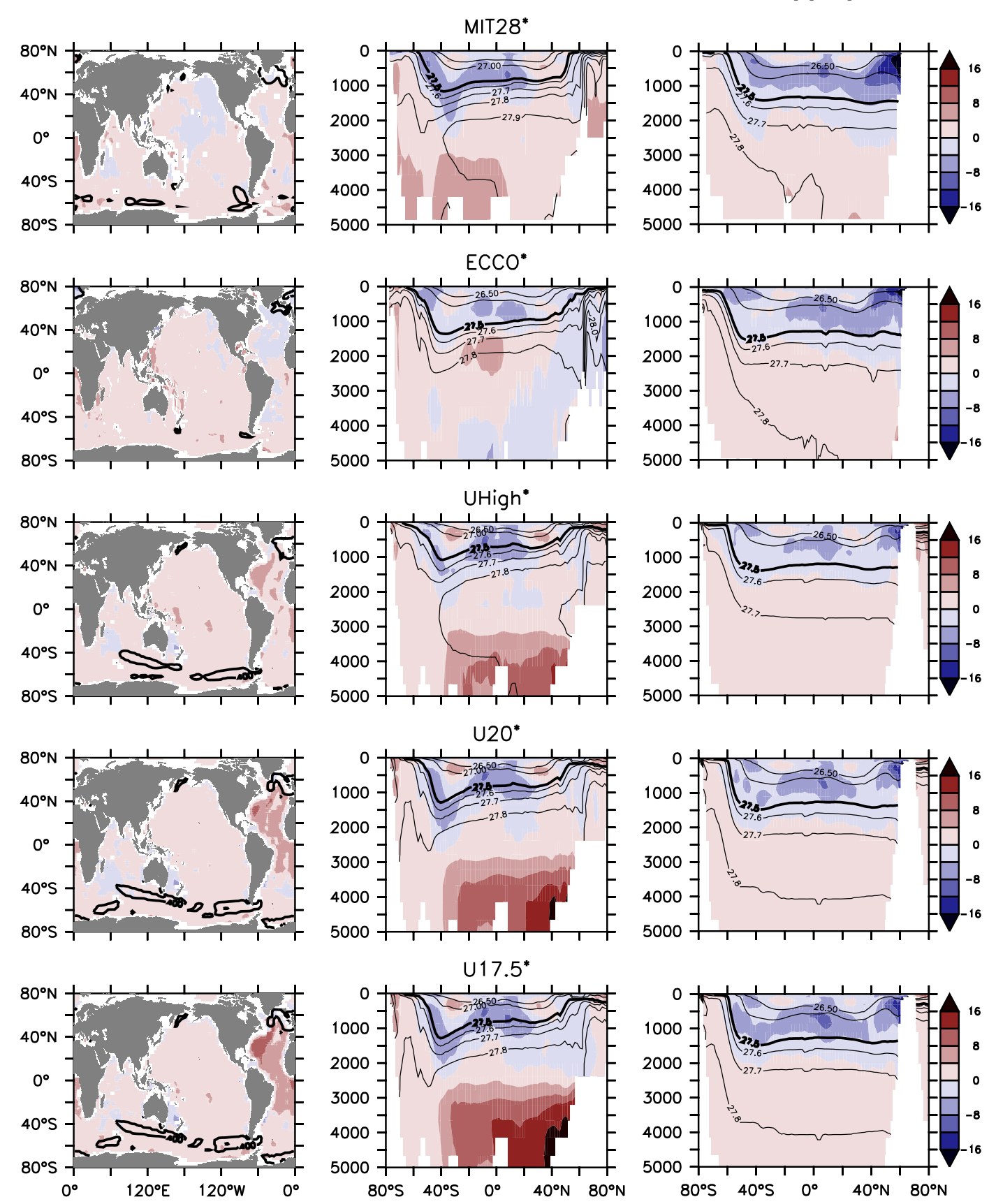

Figure S4. As Figure S3, but for nitrate. 

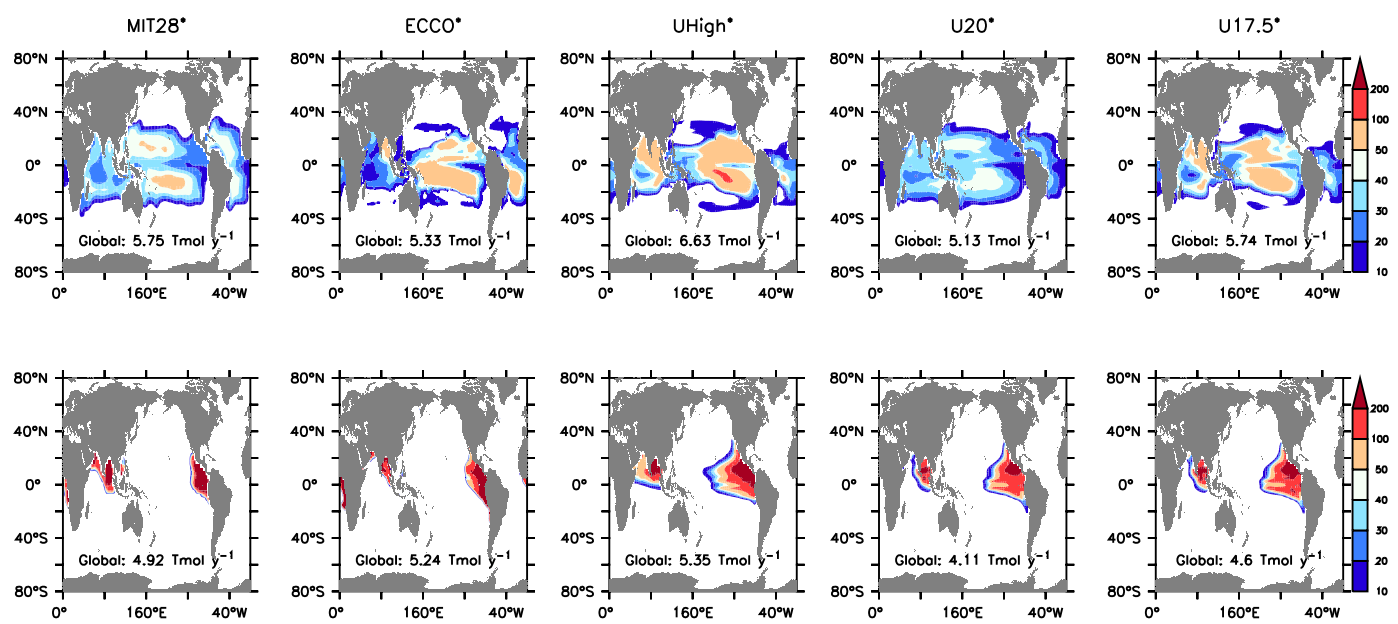

Figure S5. Vertically integrated nitrogen fixation (top) and denitrification (bottom) in the optimal model runs. Fluxes (colourbar) are in mmol $\mathrm{N} \mathrm{m}^{-2} \mathrm{y}^{-1}$. Numbers in panels give globally integrated flux. 
1500-5000m
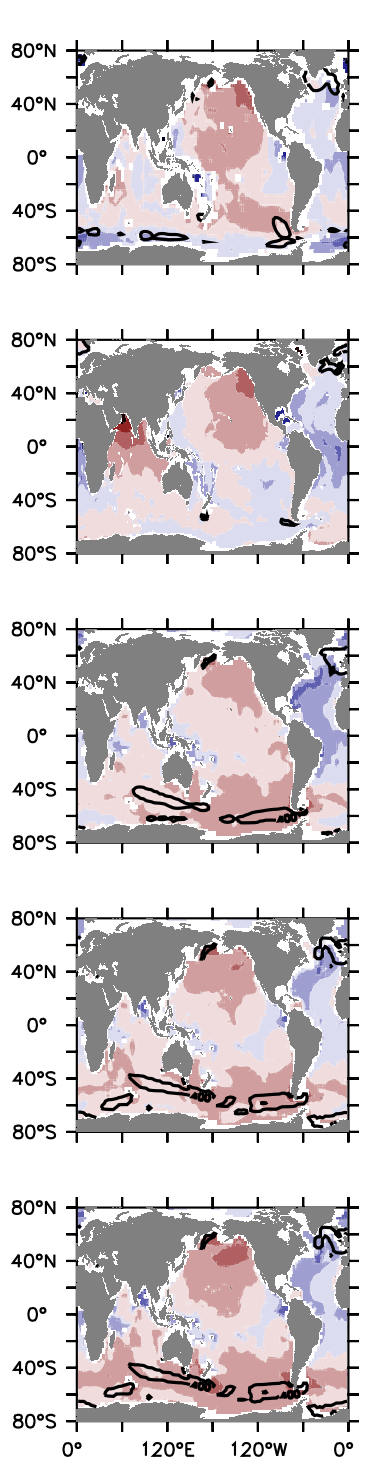

Atlantic

MIT28*

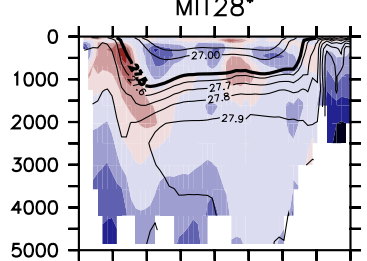

ECCO*

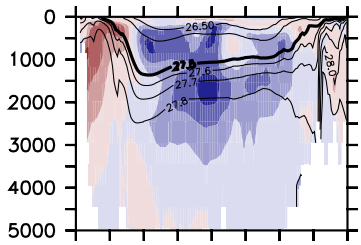

UHigh*

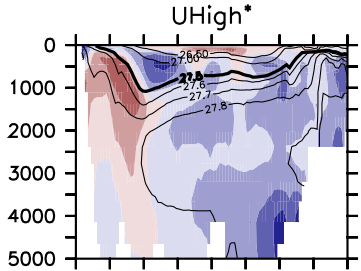

U20*

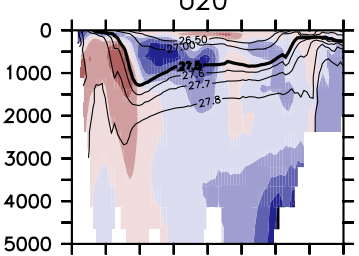

U 17.5*

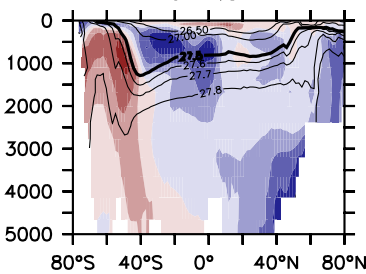

Pacific
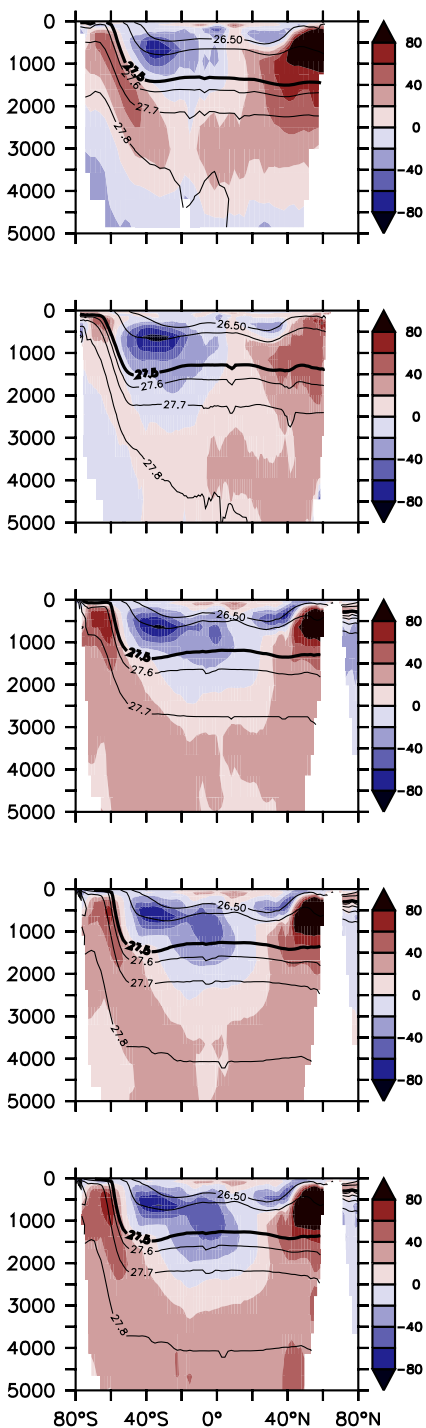

Figure S6. As Figure S3, but for oxygen. 

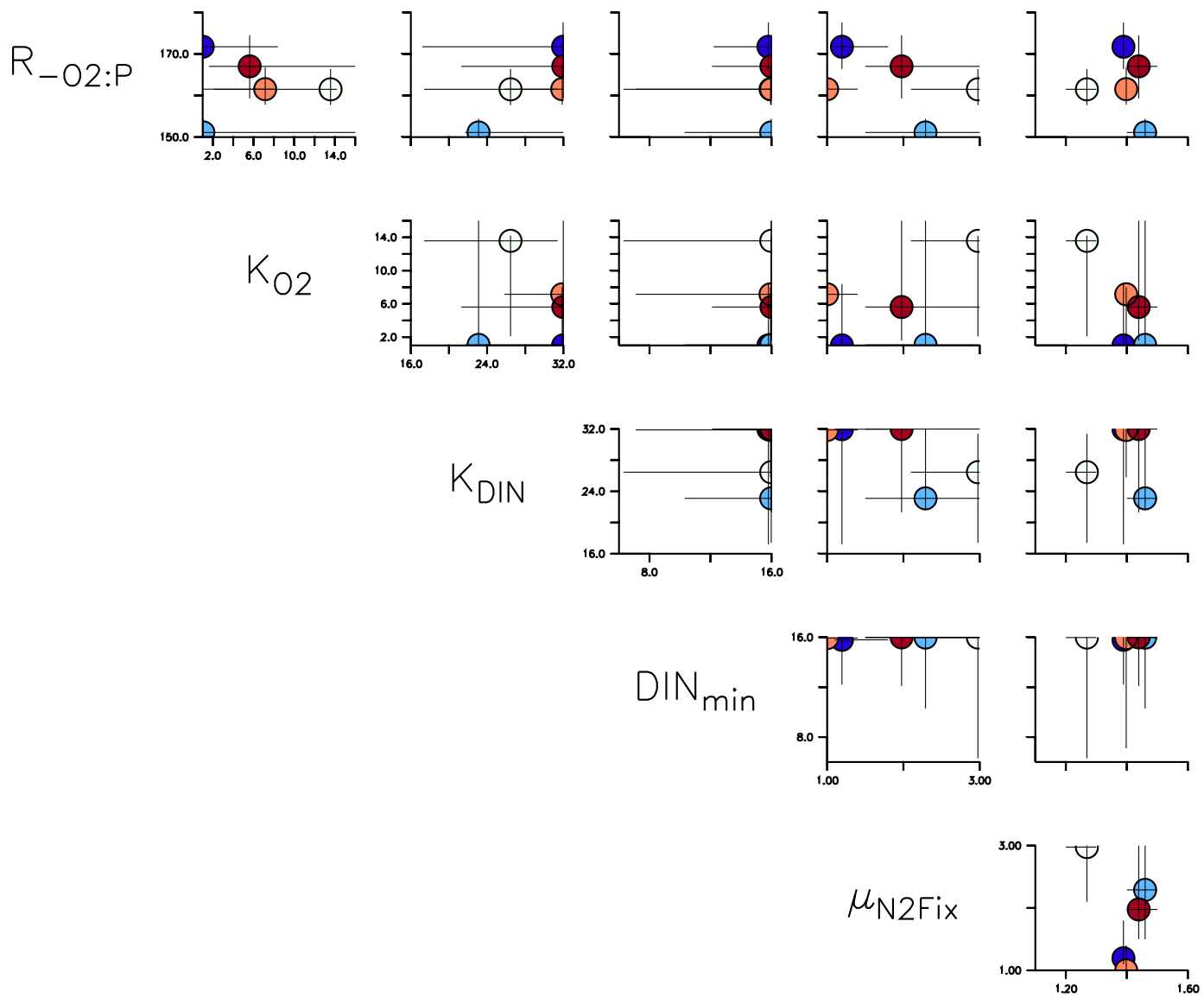

b

Figure S7. Pairs of optimal parameters for the five model optimisations. Colour indicates model type. Dark blue: MIT28*. Light blue: ECCO*. White: UHigh* . Orange: U20*. Dark red: U17.5* . Horizontal and vertical bars indicate the uncertainty range (parameters for which misfit $J_{i}$ deviates less than $1 \%$ from the optimal misfit $J^{*}\left(J_{i} / J^{*}-1 \leq \Delta_{J}\right.$, with $\left.\Delta_{J}=0.01\right)$. 

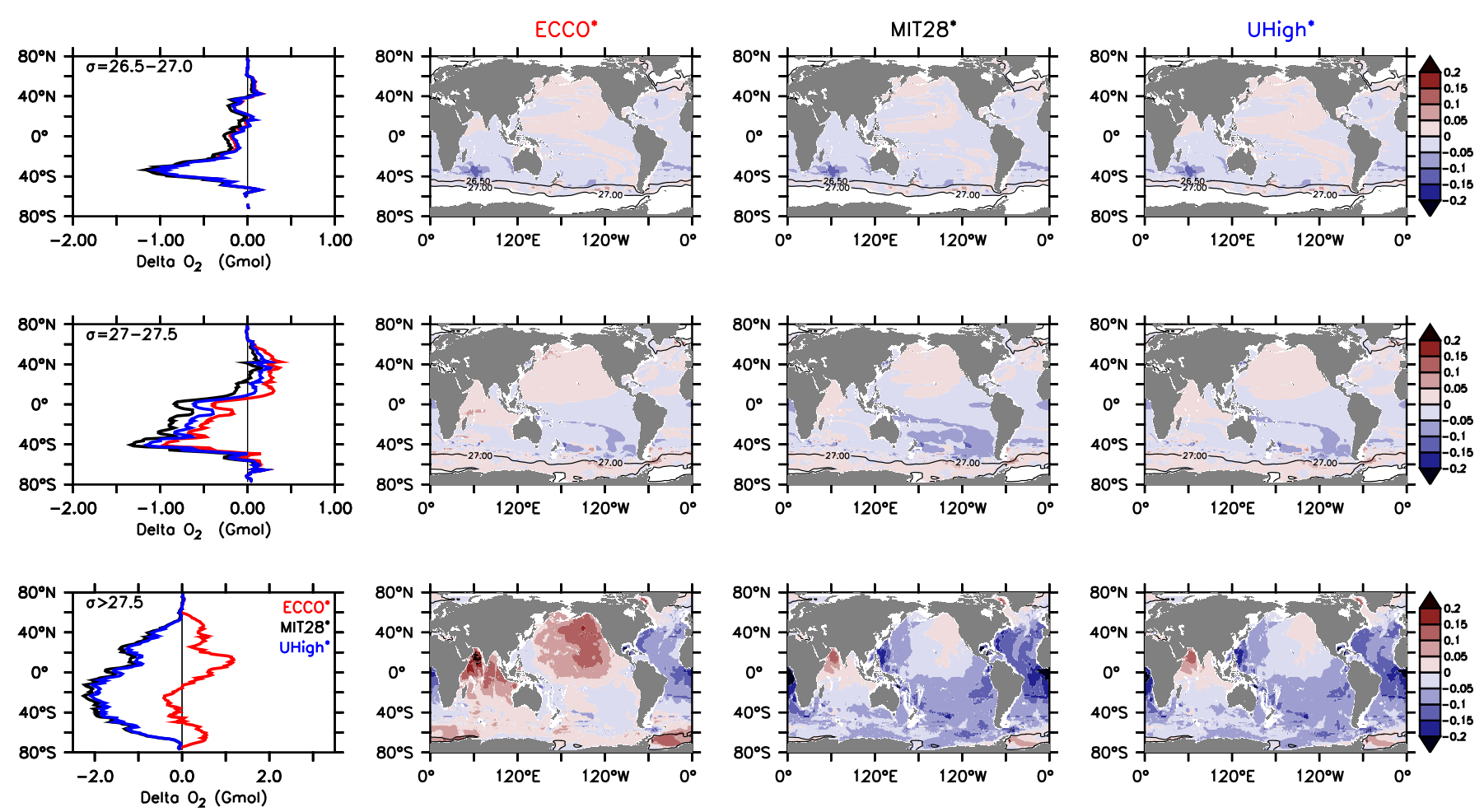

Figure S8. Vertically integrated deviation $\left(\mathrm{kmol} \mathrm{m}^{-2}\right)$ of simulated to observed oxygen in three different domains, for simulations with ECCO circulation and the three different parameter sets of ECCO*, MIT28* and UHigh ${ }^{*}$ ). Upper panels: for domain between $\sigma=26.5$ and $\sigma=27.0$. Middle panels: for domain between $\sigma=27.0$ and $\sigma=27.5$. Lower panels: for domain of $\sigma>27.5$. Thin lines denote the outcrop areas of the water masses. The left panels show the bias of zonal integrals (in $\mathrm{Pmol}_{2}$ ) for simulations with parameters of ECCO* (red), UHigh* (blue) and MIT28* (black). 